\title{
Return to work after ischemic stroke in young adults
}

A registry-based follow-up study

Karoliina Aarnio, MD, * Jorge Rodríguez-Pardo, MD,* Bob Siegerink, PhD, Juliane Hardt, Dipl-Psych, Jenna Broman, MD, Lauri Tulkki, MD, Elena Haapaniemi, MD, PhD, Markku Kaste, MD, PhD,

Turgut Tatlisumak, MD, PhD, and Jukka Putaala, MD, PhD

Neurology ${ }^{\circledR}$ 2018;91:e1909-e1917. doi:10.1212/WNL.0000000000006510

\section{Abstract}

\section{Objective}

We aimed to investigate the proportion of young patients not returning to work (NRTW) at 1 year after ischemic stroke (IS) and during follow-up, and clinical factors associated with NRTW.

\section{Methods}

Patients from the Helsinki Young Stroke Registry with an IS occurring in the years 1994-2007, who were at paid employment within 1 year before IS, and with NIH Stroke Scale score $\leq 15$ points at hospital discharge, were included. Data on periods of payment came from the Finnish Centre for Pensions, and death data from Statistics Finland. Multivariate logistic regression analyses assessed factors associated with NRTW 1 year after IS, and lasagna plots visualized the proportion of patients returning to work over time.

\section{Results}

We included a total of 769 patients, of whom 289 (37.6\%) were not working at 1 year, 323 (42.0\%) at 2 years, and $361(46.9 \%)$ at 5 years from IS. When adjusted for age, sex, socioeconomic status, and NIH Stroke Scale score at admission, factors associated with NRTW at 1 year after IS were large anterior strokes, strokes caused by large artery atherosclerosis, high-risk sources of cardioembolism, and rare causes other than dissection compared with undetermined cause, moderate to severe aphasia vs no aphasia, mild and moderate to severe limb paresis vs no paresis, and moderate to severe visual field deficit vs no deficit.

\section{Conclusions}

NRTW is a frequent adverse outcome after IS in young adults with mild to moderate IS. Clinical variables available during acute hospitalization may allow prediction of NRTW.

\author{
Correspondence \\ Dr. Aarnio \\ karoliina.aarnio@helsinki.fi
}

\section{RELATED ARTICLE}

\section{Editorial}

Return to work in young adults with stroke: Another catastrophe in a catastrophic disease Page 905

\footnotetext{
*These authors contributed equally to this work.

From Clinical Neurosciences (K.A., J.B., L.T., E.H., M.K., T.T., J.P.), Neurology, University of Helsinki and Department of Neurology, Helsinki University Hospital; Department of Neurology (J.R.-P.), Helsinki University Hospital, Finland; Department of Neurology (J.R.-P.), La Paz University Hospital, Madrid, Spain; Center for Stroke Research Berlin (B.S., J.H.), Institute of Biometry and Clinical Epidemiology (J.H.), Charité-Universitätsmedizin Berlin, corporate member of Freie Universität Berlin, Humboldt-Universität zu Berlin, and Berlin Institute of Health (BIH), Berlin Germany; Berlin Institute of Health (BIH) (J.H.), Berlin, Germany. Clinical Research Unit (CRU) (J.H.), Berlin Institute of Health (BIH), Berlin, Germany; Department of Clinical Neuroscience (T.T.), Institute of Neurosciences and Physiology, Sahlgrenska Academy, University of Gothenburg; and Department of Neurology (T.T.), Sahlgrenska University Hospital, Gothenburg, Sweden.

Go to Neurology.org/N for full disclosures. Funding information and disclosures deemed relevant by the authors, if any, are provided at the end of the article.

The Article Processing Charge was funded by Helsinki and Uusimaa Hospital District.
}

This is an open access article distributed under the terms of the Creative Commons Attribution-NonCommercial-NoDerivatives License 4.0 (CC BY-NC-ND), which permits downloading and sharing the work provided it is properly cited. The work cannot be changed in any way or used commercially without permission from the journal. 


\section{Glossary}

AIC = Akaike information criterion; AUC = area under the curve; IS = ischemic stroke; NIHSS = NIH Stroke Scale; NRTW = not returning to work; RTW = return to work; SES = socioeconomic status; TOAST = Trial of Org 10172 in Acute Stroke Treatment.

Recent data suggest a rising incidence of ischemic stroke (IS) in young populations. ${ }^{1}$ Return to work (RTW) is the primary goal in the rehabilitation process of most patients of working age, and it is associated with improved well-being and life satisfaction. ${ }^{2}$ From a societal perspective, costs arising from reduced production caused by sick leave, early retirement, and untimely death are estimated to be approximately $25 \%$ of the total costs of stroke care. ${ }^{3}$

The proportion of patients that RTW following stroke ranges from $0 \%$ to $100 \%$, with a mean of $44 \%$ across studies. ${ }^{4}$ Suggested factors related to not returning to work (NRTW) after stroke include higher NIH Stroke Scale (NIHSS) score at admission, duration of follow-up, and number of early cognitive deficits. ${ }^{5,6}$ However, some studies have small sample sizes, have ischemic and hemorrhagic strokes as well as TIA patients included, and lack information on the presence of confounding bias, for example by stroke severity and etiology. ${ }^{5-8}$

Our aim was to study NRTW after IS in young adults based on systematic data recorded in a nationwide registry. We determined the proportion of young adults NRTW at 1 year after IS and over time, and explored factors associated with NRTW, including etiologic subtype of IS, and severity of neurologic deficits at discharge.

\section{Methods}

\section{Study population}

The Department of Neurology at the Helsinki University Hospital has the only neurologic emergency unit for a population of approximately 1.5 million people. All 1,008 consecutive patients aged 15 to 49 years with a first-ever IS treated in the Department of Neurology, Helsinki University Hospital, from January 1994 to May 2007, were identified from a prospective computerized hospital discharge database and were included in the Helsinki Young Stroke Registry. ${ }^{9}$ The original World Health Organization definition of stroke was used, but also those with imaging-positive findings of IS despite short symptom duration were included. ${ }^{10}$ As we wanted to study stroke patients being able to RTW, the study population was restricted to patients with a total score of $\leq 15$ on the NIHSS at discharge from the first acute-care hospitalization. We excluded patients with false primary diagnosis and patients who were lost to follow-up.

\section{Baseline data}

Baseline laboratory and other diagnostic tests have been described in full previously. ${ }^{9}$ All patients underwent brain CT or
MRI. As a measure of socioeconomic status (SES), we used patients' occupational status, categorized as upper-whitecollar worker, lower-white-collar worker, blue-collar worker, other (entrepreneur, student, pensioner, and unemployed), and unknown SES. ${ }^{11}$ We classified the etiology of IS with Trial of Org 10172 in Acute Stroke Treatment (TOAST) criterion, ${ }^{12}$ with special modifications because of our young stroke population. We categorized cardioembolism as being from high- and low-risk sources, ${ }^{13}$ the former including all other sources except patent foramen ovale or atrial septal aneurysm. We separated cervical artery dissections from other causes of IS. We included data on symptoms and findings at discharge from the first acute-care hospitalization as reported by the physician in the medical records as follows. We trichotomized hemiparesis of the limbs into mild if any limb had drift as in NIHSS item 5 and 6 resulting in 1 point, ${ }^{14}$ and moderate to severe if any limb had more weakness than just a drift resulting in 2 to 4 points. We trichotomized aphasia into no aphasia (NIHSS item $9=0$ points), mild (NIHSS item $9=1$ point), or moderate to severe (NIHSS item $9=2-3$ points). We trichotomized visual field deficit as no (NIHSS item $3=$ 0 points), partial hemianopia (NIHSS item $3=1$ point, mild visual field deficit), and complete or bilateral hemianopia or cortical blindness (NIHSS item $3=2-3$ points, moderate to severe visual field deficit). We included sensory deficit of the arm, face, or leg dichotomously either as having deficit or not.

\section{Follow-up data}

We obtained data on work history from the Finnish Centre for Pensions from 1992 to the end of 2011 (periods of payment for 929 patients [92.2\%]). Pension security covers virtually all paid work in Finland. Thus, the earnings and accrual registry contains practically all dates for earnings from the private and public sector as well as for entrepreneurs aged 18 to 68 years. ${ }^{15}$ We included only patients with paid employment within 1 year before IS. Follow-up time started at IS date, and ended at death or at December 31,2011, whichever occurred first. Data on deaths from 1994 to the end of 2011 came from Statistics Finland. ${ }^{16}$

\section{Standard protocol approvals, registrations, and patient consents}

The institutional ethics committee gave permission for this study. Informed consent was not needed in this registry-based study without direct patient contacts.

\section{Statistical analyses}

We analyzed the data using SPSS 22.0 for Windows (IBM, Armonk, NY), SAS 9.4 for Windows (SAS Institute, Cary, $\mathrm{NC}$ ), and $\mathrm{R}^{17}$ The characteristics of patients included were 
presented with descriptive statistics (numbers and percentages; medians and interquartile ranges) for the complete analysis set of the study population and stratified for the outcome variable of this study. In explorative analyses, we tested the associations of the patient characteristics surveyed in this study with NRTW using univariate and multivariate logistic regression analyses and reported their results with odds ratios and corresponding 95\% confidence intervals. Variables with odds ratios in the univariate regression analyses that significantly differed from the reference categories $(p<$ 0.05 ) were included in the multivariate logistic regression analyses. Some of the variables with a significant association with the outcome in the univariate regression analyses, especially variables characterizing the clinical status of a patient, are known to be intercorrelated from clinical and published evidence. Therefore, we checked the intercorrelations of the included variables in advance. In addition, we applied standard multicollinearity analyses (tolerance, variance inflation factor) to avoid standard error inflation for the regression models. ${ }^{18}$ In the first multivariate regression model (model 1 ), the enter method estimated a full multivariate model with all significant univariate variables included. In addition, 2 multivariate logistic regression models with reduced sets of variables were estimated using different strategies of variable selection in search for the most parsimonious model. For multivariate model 2, we used a forward stepwise selection algorithm based on the likelihood ratio statistic of each variable. For model 3, we applied manual stepwise variable selection starting with a basic model of relevant covariables (age, sex, SES) and adding variables based on the significance of the variables $(p<0.05)$ and their pseudo- $R^{2}$ s (Nagelkerke $\left.R^{2}\right)$ in the univariate model, beginning with the highest pseudo- $R^{2}$ until the addition of new variables did not result in relevant further increases of the pseudo- $R^{2}$ of the model. ${ }^{18}$ When this process resulted in similar increases of the pseudo- $R^{2}$ for 2 variables, the variable with higher clinical relevance was chosen. The 3 different models were then compared by assessing their results in Hosmer-Lemeshow goodness-of-fit test, Akaike information criterion (AIC), and area under the curve (AUC) values based on receiver operating curve analyses for the assessment of the discriminative ability of the models. ${ }^{18-20}$ We applied significance testing in this explorative study solely with the purpose of discovering tendencies in associations, and it was not done for confirmatory purposes, so no adjustment for multiple testing was applied. Lasagna plotsgraphical tools for the display of multiple longitudinal outcomes similar to heat maps used in the genomics literature-were created using $\mathrm{R}$ and the data on employment status available during 15-year follow-up after IS, divided in 14 intervals of 1 year each. ${ }^{21}$ For each interval, we determined which patients did RTW for at least 1 day of paid employment and which ones did not. Based on the initial lasagna plot of all patients in the analysis $(n=769)$, patients were then sorted per interval (within-column sorting) according to their status (RTW, NRTW, no data available on employment status). In addition, the multiply sorted lasagna plot was stratified for sex and age.

\section{Data availability}

We have documented the data, methods, and materials used to conduct the research in this report. The individual patient data are not publicly available because of legal restrictions. See data available from Dryad (tables e-1 to e-5, doi.org/10.5061/ dryad.p7n02t0).

\section{Results}

We included a total of 769 patients, with a mean follow-up of 10.5 (range 0.1-18.0) years, after the exclusion of patients who were not at work during the last year before IS, with neurologic evaluation at discharge not available, and those with NIHSS score $>15$ at discharge from the hospital (figure 1). Of these 769 patients, 289 (37.6\%) were not working at 1 year, $323(42.0 \%)$ at 2 years, and 361 (46.9\%) at 5 years after their IS. Similarly, the percentages were

Figure 1 Flowchart of patients included in the study

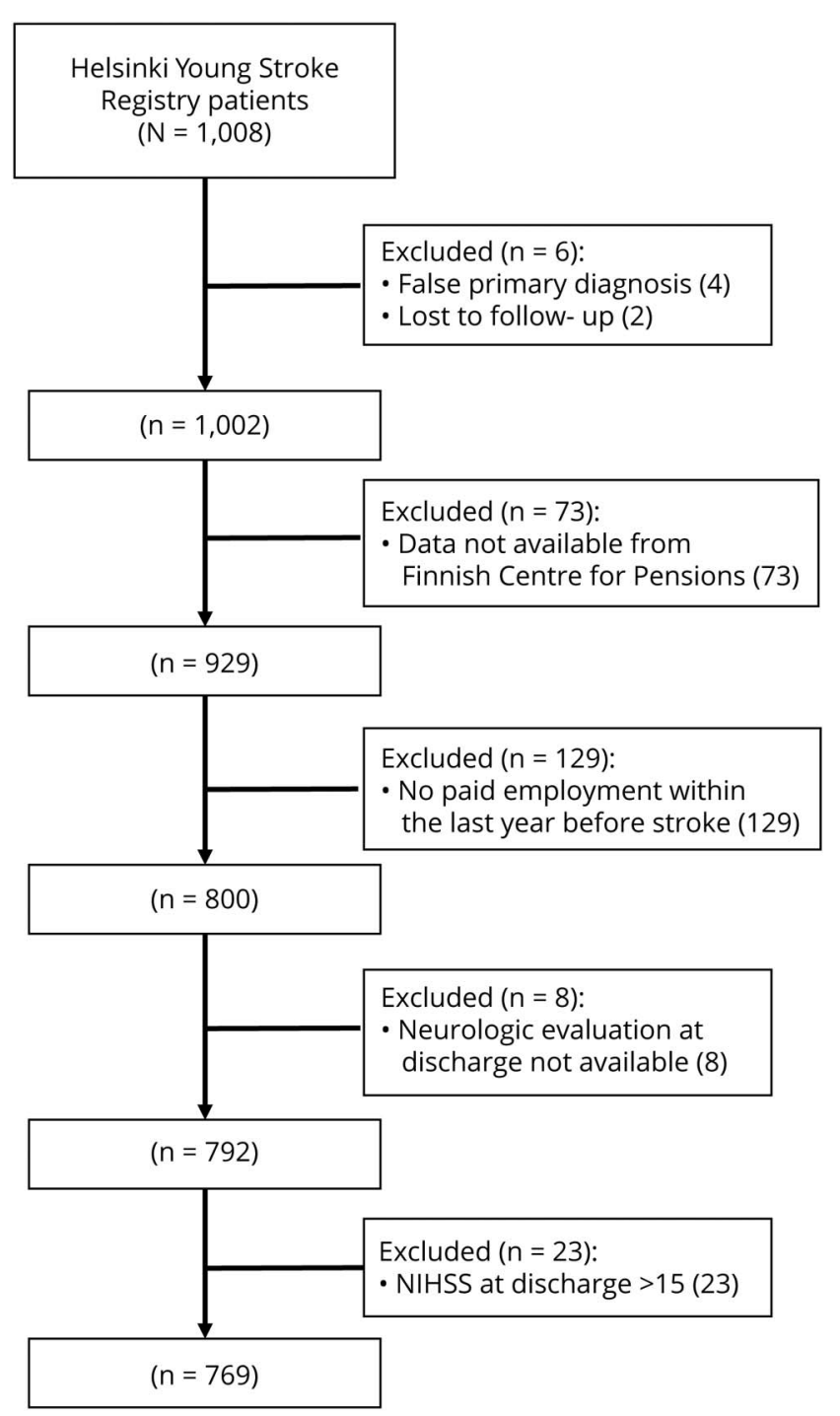

NIHSS = NIH Stroke Scale. 
Table 1 Characteristics of patients with IS ( $n=769)$

\begin{tabular}{|c|c|}
\hline Characteristic & \\
\hline Age at IS, y & $44(37-47)$ \\
\hline Sex, male & $478(62.2)$ \\
\hline Socioeconomic status & \\
\hline Upper-white-collar worker & $98(12.7)$ \\
\hline Lower-white-collar worker & $219(28.5)$ \\
\hline Blue-collar worker & $346(45.0)$ \\
\hline Other or unknown & $106(13.8)$ \\
\hline Cigarette smoking & $335(43.6)$ \\
\hline Cardiovascular disease & $68(8.8)$ \\
\hline Diabetes mellitus type 1 & $27(3.5)$ \\
\hline Diabetes mellitus type 2 & $43(5.6)$ \\
\hline Heavy drinking & $74(9.6)$ \\
\hline Hypertension & 307 (39.9) \\
\hline NIHSS score at admission & $3(1-6)$ \\
\hline $0-5$ & $570(74.1)$ \\
\hline $6-10$ & $106(13.8)$ \\
\hline $11-15$ & $53(6.9)$ \\
\hline $16-20$ & $32(4.2)$ \\
\hline$>20$ & $8(1.0)$ \\
\hline Infarct size & \\
\hline Small & $349(45.4)$ \\
\hline Medium & $220(28.6)$ \\
\hline Large anterior & $109(14.2)$ \\
\hline Large posterior & $91(11.8)$ \\
\hline TOAST modified & \\
\hline Large artery atherosclerosis & $50(6.5)$ \\
\hline High-risk sources of cardioembolism & $69(9.0)$ \\
\hline Low-risk sources of cardioembolism & $78(10.1)$ \\
\hline Small vessel occlusion & $109(14.2)$ \\
\hline Internal carotid artery dissection & $60(7.8)$ \\
\hline Vertebral artery dissection & $67(8.7)$ \\
\hline Rare causes other than dissection & $79(10.3)$ \\
\hline Undetermined causes & $257(33.4)$ \\
\hline Symptoms and findings at hospital disc & \\
\hline Mild aphasia & 99 (12.9) \\
\hline Moderate to severe aphasia & $63(8.2)$ \\
\hline Mild limb paresis & $104(13.5)$ \\
\hline Moderate to severe limb paresis & $100(13.0)$ \\
\hline
\end{tabular}

Table 1 Characteristics of patients with IS $(n=769)$ (continued)

\begin{tabular}{lc}
\hline Characteristic & \\
\hline Sensory deficit $^{\text {a }}$ & $262(34.1)$ \\
\hline Mild visual field deficit $^{\mathbf{b}}$ & $62(8.1)$ \\
\hline Moderate to severe visual field deficit $^{\mathbf{b}}$ & $52(6.8)$ \\
\hline NIHSS score at discharge & $1(0-3)$ \\
\hline $\mathbf{0 - 5}$ & $656(85.3)$ \\
\hline $\mathbf{6 - 1 0}$ & $78(10.1)$ \\
\hline $\mathbf{1 1 - 1 5}$ & $35(4.6)$
\end{tabular}

Abbreviations: IS = ischemic stroke; NIHSS = NIH Stroke Scale; TOAST = Trial of Org 10172 in Acute Stroke Treatment.

Data are $\mathrm{n}(\%)$ or median (interquartile range).

$\mathrm{a} n=768$.

${ }^{b} \mathrm{n}=766$.

$39.3 \%$ at 1 year, $43.7 \%$ at 2 years, and $48.4 \%$ at 5 years from IS, if including also those patients with NIHSS score $>15$ ( $\mathrm{n}=$ 792 ). Among the 23 patients with NIHSS score $>15$ points at discharge, of whom 11 patients died before discharge and 2 more patients died within 3 months, only one returned to work at 1 year after IS, but then at 2 years was no longer working, and one more patient had returned to work at 5 years after IS, resulting in only $8.7 \%$ of these patients returning to work at some point after IS. The baseline characteristics of the study population are described in table 1 . All in all, 15 patients $(2.0 \%)$ had a history of drug abuse any time before IS, and only 3 patients $(0.4 \%)$ had used illicit drugs 1 month before IS. To show the effect of the selection process, we also described the characteristics of excluded patients who were not at paid employment during the last year before their stroke $(n=129)$ (data available from Dryad, table e-1, doi.org/10.5061/dryad. $\mathrm{p} 7 \mathrm{n} 02 \mathrm{t} 0$ ). Figure 2, A-D, shows the proportion of patients having returned to work after IS during follow-up in the form of lasagna plots.

Factors associated with NRTW at 1 year after IS in the univariate analysis are presented in table 2 . In longer follow-up, we also found higher rates of NRTW among patients with type 1 diabetes and small vessel occlusion causing the index event at 2 and 5 years after IS, and among lower-white-collar workers at 5 years after IS. In addition, low-risk sources of cardioembolism causing the index event (vs undetermined cause) was associated with lower rates of NRTW at 2 years after IS (data available from Dryad, table e-2, doi.org/10. 5061/dryad.p7n02t0).

Models 1 and 2 of the multivariate logistic regression analyses (full model and model with automated stepwise variable selection) are presented in data available from Dryad (table e-3, doi.org/10.5061/dryad.p7n02t0). The results of model 1 were similar even after also including those patients with NIHSS score $>15$ at discharge (data not shown). In the final 
Figure 2 Lasagna plots on employment trajectories over time after ischemic stroke

A

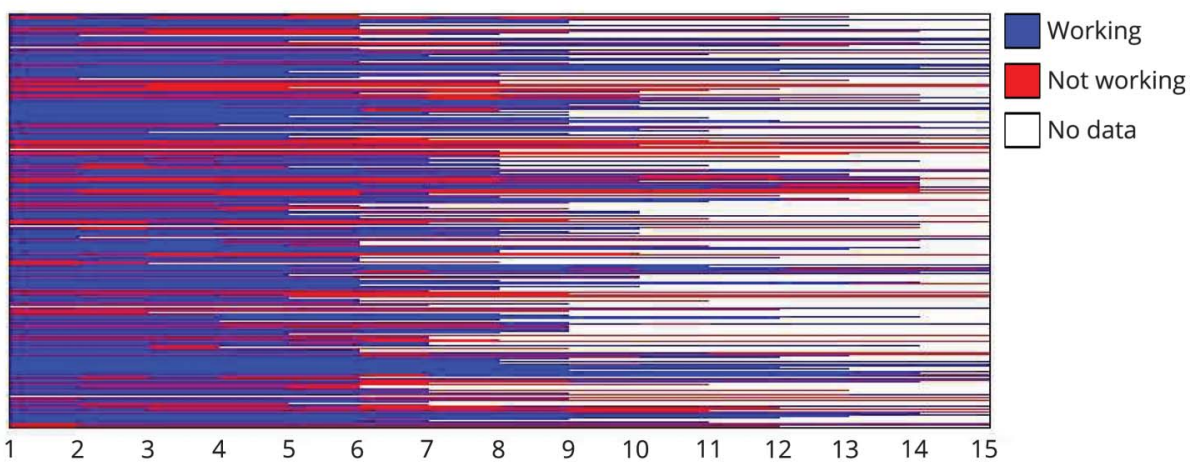

B

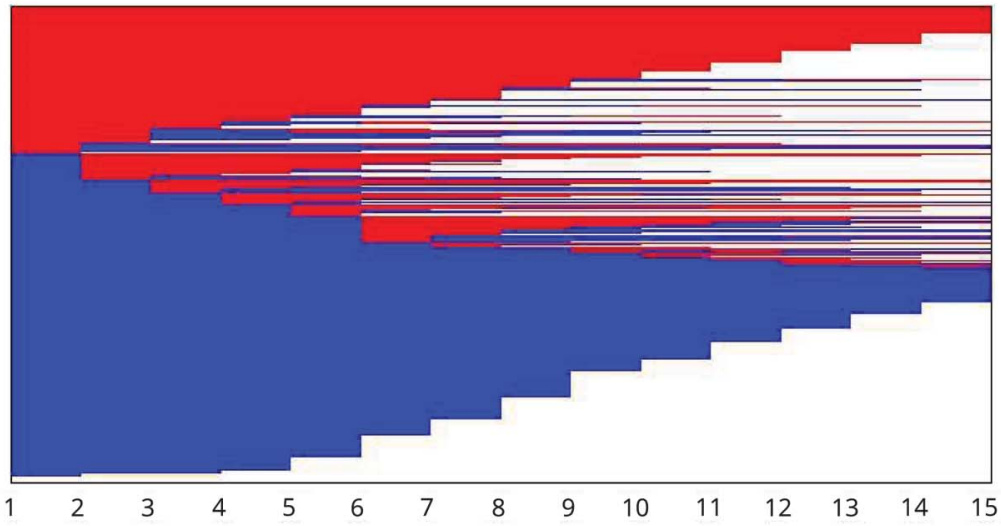

C

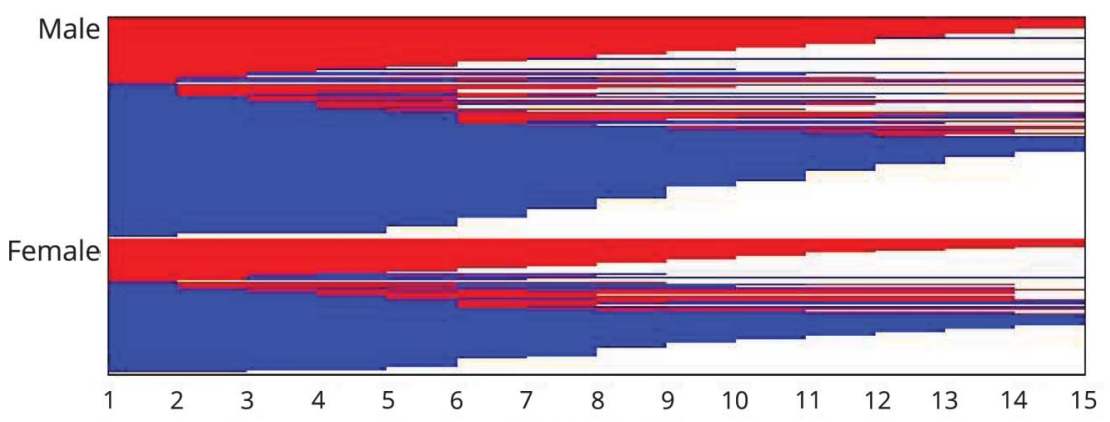

D

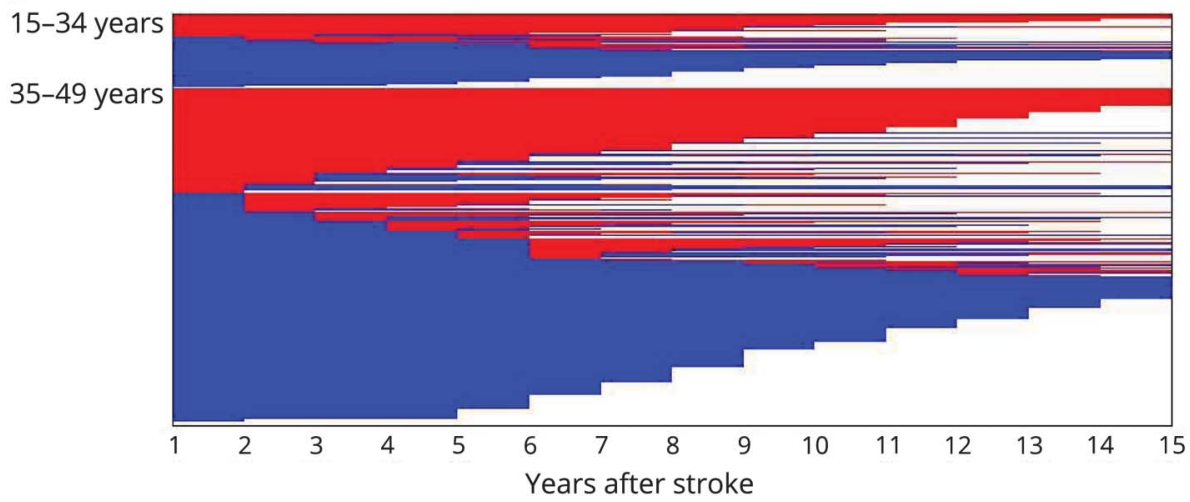

(A) Initial lasagna plot: employment trajectories for patients with ischemic stroke 1 to 15 years after stroke. (B) Multiply within-column sorted lasagna plot: employment trajectories for patients with ischemic stroke 1 to 15 years after stroke. (C) Multiply within-column sorted lasagna plot stratified for sex: employment trajectories for patients with ischemic stroke 1 to 15 years after stroke. (D) Multiply within-column sorted lasagna plot stratified for age groups (15-34, 35-49): employment trajectories for patients with ischemic stroke 1 to 15 years after stroke. 
Table 2 Numbers and univariate logistic regression analyses for NRTW at 1 year after IS

\begin{tabular}{|c|c|c|c|}
\hline Characteristic & $\operatorname{RTW}(n=480)$ & NRTW $(n=289)$ & OR $(95 \% \mathrm{Cl})$ \\
\hline Age at IS, y & $43(36-47)$ & $45(38-48)$ & $1.02(1.00-1.04)$ \\
\hline Sex, male & $280(58.3)$ & $198(68.5)$ & $1.55(1.14-2.11)$ \\
\hline Upper-white-collar worker & $79(16.5)$ & $19(6.6)$ & Ref \\
\hline Lower-white-collar worker & $159(33.1)$ & $60(20.8)$ & $1.57(0.88-2.81)$ \\
\hline Blue-collar worker & $192(40.0)$ & $154(53.3)$ & $3.34(1.94-5.75)$ \\
\hline Other or unknown & $50(10.4)$ & $56(19.4)$ & $4.66(2.48-8.74)$ \\
\hline Cardiovascular disease & $29(6.0)$ & $39(13.5)$ & $2.43(1.46-4.02)$ \\
\hline Cigarette smoking & $190(39.6)$ & $145(50.2)$ & $1.54(1.15-2.06)$ \\
\hline Diabetes mellitus type 1 & $15(3.1)$ & $12(4.2)$ & $1.34(0.62-2.91)$ \\
\hline Diabetes mellitus type 2 & $18(3.8)$ & $25(8.7)$ & $2.43(1.30-4.54)$ \\
\hline Heavy drinking & $31(6.5)$ & $43(14.9)$ & $2.53(1.56-4.12)$ \\
\hline Hypertension & $177(36.9)$ & $130(45.0)$ & $1.40(1.04-1.88)$ \\
\hline NIHSS score at admission & $2(1-4)$ & $4(2-10)$ & \\
\hline $0-5$ & $411(85.6)$ & $159(55.0)$ & Ref \\
\hline $6-10$ & $42(8.8)$ & $64(22.1)$ & $3.94(2.56-6.06)$ \\
\hline $11-15$ & $18(3.8)$ & $35(12.1)$ & $5.03(2.77-9.13)$ \\
\hline $16-20$ & $7(1.5)$ & $25(8.7)$ & $9.23(3.91-21.77)$ \\
\hline$>\mathbf{2 0}$ & $2(0.4)$ & $6(2.1)$ & $7.75(1.55-38.82)$ \\
\hline Small infarct size & $248(51.7)$ & $101(34.9)$ & Ref \\
\hline Medium-sized infarct & $144(30.0)$ & $76(26.3)$ & $1.30(0.90-1.86)$ \\
\hline Large anterior infarct & $25(5.2)$ & $84(29.1)$ & $8.25(4.99-13.64)$ \\
\hline Large posterior infarct & $63(13.1)$ & $28(9.7)$ & $1.09(0.66-1.80)$ \\
\hline \multicolumn{4}{|l|}{ TOAST etiology } \\
\hline Undetermined causes & $184(38.3)$ & $73(25.3)$ & Ref \\
\hline Large artery atherosclerosis & $14(2.9)$ & $36(12.5)$ & $6.48(3.30-12.72)$ \\
\hline CEH & $32(6.7)$ & $37(12.8)$ & $2.91(1.69-5.03)$ \\
\hline CEL & $61(12.7)$ & $17(5.9)$ & $0.70(0.39-1.28)$ \\
\hline Small vessel occlusion & $69(14.4)$ & $40(13.8)$ & $1.46(0.91-2.35)$ \\
\hline ICAD & $22(4.6)$ & $38(13.1)$ & $4.35(2.41-7.86)$ \\
\hline ROD & $44(9.2)$ & $35(12.1)$ & $2.00(1.19-3.37)$ \\
\hline Vertebral artery dissection & $54(11.3)$ & $13(4.5)$ & $0.61(0.31-1.18)$ \\
\hline No aphasia & $415(86.5)$ & $192(66.4)$ & Ref \\
\hline Mild aphasia & $53(11.0)$ & $46(15.9)$ & $1.88(1.22-2.89)$ \\
\hline Moderate-severe aphasia & $12(2.5)$ & $51(17.6)$ & $9.19(4.79-17.63)$ \\
\hline No limb paresis & $414(86.3)$ & $151(52.2)$ & Ref \\
\hline Mild limb paresis & $49(10.2)$ & $55(19.0)$ & $3.08(2.01-4.72)$ \\
\hline Moderate-severe limb paresis & $17(3.5)$ & $83(28.7)$ & $13.39(7.69-23.30)$ \\
\hline Sensory deficit ${ }^{a}$ & $124(25.9)$ & $138(47.8)$ & $2.62(1.92-3.56)$ \\
\hline
\end{tabular}


Table 2 Numbers and univariate logistic regression analyses for NRTW at 1 year after IS (continued)

\begin{tabular}{|c|c|c|c|}
\hline Characteristic & $\operatorname{RTW}(n=480)$ & NRTW $(n=289)$ & OR $(95 \% \mathrm{Cl})$ \\
\hline No visual field deficit ${ }^{b}$ & $416(87.0)$ & $236(81.9)$ & Ref \\
\hline Mild visual field deficit ${ }^{b}$ & $42(8.8)$ & $20(6.9)$ & $0.84(0.48-1.46)$ \\
\hline Moderate-severe deficit ${ }^{b}$ & $20(4.2)$ & $32(11.1)$ & $2.82(1.58-5.04)$ \\
\hline NIHSS score at discharge & $1(0-2)$ & $3(1-7)$ & \\
\hline $0-5$ & $461(96.0)$ & $195(67.5)$ & Ref \\
\hline $6-10$ & $16(3.3)$ & $62(21.5)$ & $9.16(5.16-16.27)$ \\
\hline $11-15$ & $3(0.6)$ & $32(11.1)$ & $25.22(7.63-83.32$ \\
\hline
\end{tabular}

Abbreviations: $\mathrm{CEH}=$ high-risk sources of cardioembolism; $\mathrm{CEL}=$ low-risk sources of cardioembolism; $\mathrm{Cl}=$ confidence interval; $I C A D=$ internal carotid artery dissection; IS = ischemic stroke; NIHSS = NIH Stroke Scale; NRTW = not returning to work; OR = odds ratio; Ref = reference; ROD = rare causes other than dissection; RTW = return to work; TOAST = Trial of Org 10172 in Acute Stroke Treatment.

Data are $\mathrm{n}(\%)$ or median (interquartile range).

${ }^{a} \mathrm{n}=768$.

${ }^{\mathrm{b}} \mathrm{n}=766$.

multivariate logistic regression model with variable selection based on Nagelkerke $R^{2}$ s and AIC values (model 3, table 3), age, sex, and SES were included in the basic model (data available from Dryad, table e-4, doi.org/10.5061/dryad.p7n02t0). Variables included in the model based on the statistical criteria were NIHSS score at admission, infarct size, modified TOAST categories, aphasia, limb paresis, and visual field deficit. In the final model 3, we found significantly higher rates of NRTW at 1 year after IS for patients who were male, blue-collar workers, or other or unknown workers (entrepreneur, student, pensioner, or unemployed) compared with upper-white-collar workers; had a large anterior stroke compared with small strokes, had IS caused by large artery atherosclerosis, high-risk sources of cardioembolism, or rare causes other than dissection, with undetermined sources of stroke as the reference category; had moderate to severe aphasia vs no aphasia, mild or moderate to severe limb paresis vs no limb paresis, and moderate to severe visual field deficit vs no visual field deficit.

All 3 different models were compared regarding their results in the Hosmer-Lemeshow goodness-of-fit test, their Nagelkerke $R^{2}$, AIC, and AUC values (data available from Dryad, table e-5, doi.org/10.5061/dryad.p7n02t0). For all 3 models, the Hosmer-Lemeshow goodness-of-fit test yielded no significant lack of fit. Compared to model 2 with an automated stepwise variable selection, model 3 with a variable selection based on Nagelkerke $R^{2}$ and AIC shows higher values of explained variance (pseudo- $R^{2}$ ) and discriminative ability (AUC). As expected, the full model with all variables assessed in this publication shows the highest values in these criteria. However, model 3 can be regarded as more efficient concerning the parsimony of the model having a lower AIC value compared with model 1 .

\section{Discussion}

In our study, the percentage of patients returning to work at 1 year after ischemic stroke $(62.4 \%)$ is within similar range of that in most previous studies. ${ }^{4-6,8}$ However, some of the previous studies also included hemorrhagic strokes, which have been described as a risk factor for NRTW. ${ }^{4,5,7,8}$ In addition, patients with severe disability at discharge (NIHSS score $>15$ ) and thus at an extremely low probability of returning to work, were excluded from our analyses.

Our study confirms the effect of SES on the probability of returning to work after IS. ${ }^{8,22}$ White-collar workers had significantly higher rates of returning to work ( $81 \%$ upper-whitecollar, $73 \%$ lower-white-collar) than blue-collar workers $(55 \%)$. It is unclear whether a higher education implies a better access to employment after stroke, as recent studies have also shown contradictory results. ${ }^{5}$ Also of interest, the median personal income declines by as much as $60 \%$ over 12 months after stroke. ${ }^{23}$ The decline in income is greater for those with a higher income initially, and for those who do not RTW. Different social classes' lifestyles and easier access to higher standards of care, as well as better social networks and type of work (office vs physical work or the need to drive vehicles) for people from higher socioeconomic classes might explain some of the higher proportion returning to work among this group, although further research on the specific reasons for social class disparities in RTW are needed.

Motor impairment appears to be one of the main clinical factors affecting vocational outcome, as $83 \%$ of the patients with moderate to severe limb paresis did not RTW at 1 year after IS. Another study also found a similar association of the function of the hemiplegic hand with RTW. ${ }^{24}$ Again, other studies have also reported that the ability to walk and run, as well as normal muscle strength were associated with RTW. ${ }^{22,25,26}$ We also noticed that moderate to severe aphasia was associated with NRTW, in accordance with a previous report. $^{22}$ 
Table 3 Multivariate binary logistic regression model 3 for not having returned to work at 1 year after IS $(n=766)$

\begin{tabular}{|c|c|}
\hline Characteristic & OR $(95 \% \mathrm{Cl})$ \\
\hline \multicolumn{2}{|l|}{ Sociodemographic variables } \\
\hline Age at IS, per y & $1.00(0.98-1.03)$ \\
\hline Sex, male & $1.53(1.04-2.25)$ \\
\hline \multicolumn{2}{|l|}{ Socioeconomic status } \\
\hline Upper-white-collar worker & Ref \\
\hline Lower-white-collar worker & $1.33(0.66-2.69)$ \\
\hline Blue-collar worker & $3.08(1.60-5.90)$ \\
\hline Other or unknown & $4.63(2.17-9.88)$ \\
\hline \multicolumn{2}{|l|}{ IS characteristics } \\
\hline \multicolumn{2}{|l|}{ NIHSS at admission } \\
\hline $0-5$ & Ref \\
\hline $6-10$ & $1.54(0.89-2.67)$ \\
\hline $11-15$ & $1.59(0.71-3.59)$ \\
\hline $16-20$ & $1.52(0.45-5.18)$ \\
\hline$\geq 20$ & $1.02(0.15-6.98)$ \\
\hline \multicolumn{2}{|l|}{ Infarct size } \\
\hline Small & Ref \\
\hline Medium & $1.09(0.70-1.71)$ \\
\hline Large anterior & $2.38(1.22-4.68)$ \\
\hline Large posterior & $1.13(0.62-2.06)$ \\
\hline \multicolumn{2}{|l|}{ TOAST modified } \\
\hline Undetermined causes & Ref \\
\hline Large artery atherosclerosis & $3.61(1.66-7.89)$ \\
\hline High-risk sources of cardioembolism & $2.21(1.17-4.18)$ \\
\hline Low-risk sources of cardioembolism & $0.70(0.34-1.43)$ \\
\hline Small vessel occlusion & $1.67(0.94-2.96)$ \\
\hline Internal carotid artery dissection & $1.12(0.51-2.48)$ \\
\hline Rare causes other than dissection & $1.98(1.08-3.63)$ \\
\hline Vertebral artery dissection & $0.88(0.42-1.83)$ \\
\hline
\end{tabular}

Symptoms and findings at hospital discharge

\begin{tabular}{|c|c|}
\hline Aphasia & \\
\hline No & Ref \\
\hline Mild & $1.34(0.80-2.26)$ \\
\hline Moderate-severe & $2.74(1.20-6.22)$ \\
\hline \multicolumn{2}{|l|}{ Limb paresis } \\
\hline No & Ref \\
\hline Mild & $2.18(1.30-3.66)$ \\
\hline
\end{tabular}

Table 3 Multivariate binary logistic regression model 3 for not having returned to work at 1 year after IS ( $\mathrm{n}=$ 766) (continued)

\begin{tabular}{ll}
\hline Characteristic & OR $(95 \% \mathrm{Cl})$ \\
\hline Moderate-severe & $6.11(2.96-12.62)$ \\
\hline Visual field deficit & \\
\hline No & Ref \\
\hline Mild & $1.14(0.59-2.21)$ \\
\hline Moderate-severe & $2.32(1.12-4.81)$ \\
\hline
\end{tabular}

Abbreviations: $\mathrm{Cl}=$ confidence interval; $I S=$ ischemic stroke; $\mathrm{NIHSS}=\mathrm{NIH}$ Stroke Scale; OR = odds ratio; Ref = reference; TOAST = Trial of Org 10172 in Acute Stroke Treatment.

Large anterior strokes showed significantly lower rates of RTW (23\%). It is not surprising that especially large anterior strokes are related to NRTW as critical higher cortical functions and cortico-subcortical circuits are affected. Indeed, a Finnish study, with patients aged 18 to 65 years, reported that a higher number of cognitive deficits was related to NRTW at 6 months from IS. ${ }^{6}$

We found a higher work dropout rate among young patients with IS in the long-term follow-up, as approximately $20 \%$ of the patients who had returned to work at 1 year were not working at 5 years after IS. A Dutch study also reported that as more time elapses from the index event, an increasing proportion of stroke survivors are left unemployed. ${ }^{5}$ It might be that the cognitive or other residual deficits after IS are only seen in the work environment, and are not visible in the neuropsychological testing that precedes the permission of a survivor of stroke to RTW. Also, symptomatic epilepsy with either poor seizure control or effects on the ability to drive vehicles might happen years after the index event and affect the patient's later ability to work. In our opinion, it is essential to investigate not only whether a patient ever returns to work, but for how long, and whether the patient can work in their former position or is confronted with downgrading with respect to their qualifications. Further studies on adjustment to work requirements, quality of vocational life, and need for reeducation after stroke are also desirable.

As strengths, our study has a large study population of only patients with IS included, with well-characterized baseline stroke characteristics, SES based on occupation, and data on the working status on a national level. Stroke severity was assessed both on hospital admission and discharge, including an itemized analysis of the remaining deficits. Data were collected from official records instead of questionnaires to reduce information bias. There are also some limitations that need to be addressed. First, the definition of work was based on the periods of payment from the Finnish Centre for Pensions, and information regarding reduced working hours was lacking, as well as possibly some self-employment or other 
activities that were not registered by the patient. Also, data on study and parenting leaves were lacking. Second, patients with severe disability at discharge and thus a high probability of NRTW, were excluded from our analyses. However, only 2 of these patients with NIHSS score $>15$ returned to work after IS and the results were similar even when including these severely affected patients into the analyses. Finally, there have been fluctuations in employment rates over the long study period because of national economic regression periods, which might have affected individuals' probability to gain work at certain sectors. Third, our results should not be extrapolated as such to countries with very differing social security systems and employment markets, as Finland has an extensive statutory social security system. ${ }^{27}$ Also, we lacked data on the possible influence of self-employment on RTW.

Our study provides new data that may help clinicians to increase knowledge on work life after IS among young patients. Clinical variables easily available during acute hospitalization because of IS are closely related to NRTW and should be considered along with previously known factors such as SES. Continuity of work life for those patients who do RTW is significantly affected, and this issue should be addressed in further studies.

\section{Author contributions}

K. Aarnio: study concept and design, acquisition of data, analysis and interpretation of data, manuscript drafting. J. Rodríguez-Pardo: study concept and design, analysis and interpretation of data, manuscript drafting. B. Siegerink: study concept and design, revision for intellectual content. J. Hardt: analysis and interpretation of data, manuscript drafting, statistical consultancy. J. Broman: acquisition of data, revision for intellectual content. L. Tulkki: acquisition of data, revision for intellectual content. E. Haapaniemi: acquisition of data, revision for intellectual content. M. Kaste: study concept and design, revision for intellectual content. T. Tatlisumak: acquisition of data, revision for intellectual content. J. Putaala: study concept and design, acquisition of data, analysis and interpretation of data, revision for intellectual content. All authors reviewed and approved the final version of the manuscript to be published.

\section{Acknowledgment}

The authors thank Tuula Kyyrä for help in receiving earningsrelated data from ETK and Ulrike Grittner, $\mathrm{PhD}$, for help in statistical guidance.

\section{Study funding}

Karoliina Aarnio received research support from the Doctoral Programme in Clinical Research of University of Helsinki, CSB Virchow Scholarship, Biomedicum Helsinki Foundation, Finnish Medical Foundation, and Helsinki-Uusimaa Hospital District, and Jukka Putaala from Helsinki-Uusimaa Hospital District and Academy of Finland.

\section{Disclosure}

The authors report no disclosures relevant to the manuscript. Go to Neurology.org/N for full disclosures.

\section{Publication history}

Received by Neurology March 28, 2018. Accepted in final form August 2, 2018.

\section{References}

1. Bejot Y, Daubail B, Jacquin A, et al. Trends in the incidence of ischaemic stroke in young adults between 1985 and 2011: the Dijon Stroke Registry. J Neurol Neurosurg Psychiatry 2014;85:509-513.

2. Vestling M, Tufvesson B, Iwarsson S. Indicators for return to work after stroke and the importance of work for subjective well-being and life satisfaction.J Rehabil Med 2003; 35:127-131.

3. Terent A, Marke LA, Asplund K, Norrving B, Jonsson E, Wester PO. Costs of stroke in Sweden: a national perspective. Stroke 1994;25:2363-2369.

4. Daniel K, Wolfe CD, Busch MA, McKevitt C. What are the social consequences of stroke for working-aged adults? A systematic review. Stroke 2009;40:e431-e440.

5. Maaijwee NA, Rutten-Jacobs LC, Arntz RM, et al. Long-term increased risk of unemployment after young stroke: a long-term follow-up study. Neurology 2014;83: 1132-1138.

6. Kauranen T, Turunen K, Laari S, Mustanoja S, Baumann P, Poutiainen E. The severity of cognitive deficits predicts return to work after a first-ever ischaemic stroke. J Neurol Neurosurg Psychiatry 2013;84:316-321.

7. Catalina-Romero C, Ruilope LM, Sanchez-Chaparro MA, et al. Factors influencing return-to-work after cerebrovascular disease: the importance of previous cardiovascular risk. Eur J Prev Cardiol 2015;22:1220-1227.

8. Glader EL, Jonsson B, Norrving B, Eriksson M. Socioeconomic factors' effect on return to work after first stroke. Acta Neurol Scand 2017;135:608-613.

9. Putaala J, Metso AJ, Metso TM, et al. Analysis of 1008 consecutive patients aged 15 to 49 with first-ever ischemic stroke: the Helsinki Young Stroke Registry. Stroke 2009; 40:1195-1203.

10. Aho K, Harmsen P, Hatano S, Marquardsen J, Smirnov VE, Strasser T. Cerebrovascular disease in the community: results of a WHO collaborative study. Bull World Health Organ 1980;58:113-130.

11. Classification of socio-economic groups 1989 [online]. Available at: stat.fi/meta/ luokitukset/sosioekon_asema/001-1989/kuvaus.html. Accessed October 23, 2015.

12. Adams HP, Bendixen BH, Kappelle LJ, et al. Classification of subtype of acute ischemic stroke: definitions for use in a multicenter clinical trial. TOAST. Trial of Org 10172 in Acute Stroke Treatment. Stroke 1993;24:35-41.

13. Ay H, Furie KL, Singhal A, Smith WS, Sorensen AG, Koroshetz WJ. An evidence-based causative classification system for acute ischemic stroke. Ann Neurol 2005;58:688-697.

14. Brott T, Adams HP Jr, Olinger CP, et al. Measurements of acute cerebral infarction: a clinical examination scale. Stroke 1989;20:864-870.

15. Finnish Center for Pensions. Rekisteriseloste [online]. Available at: https://www.etk.fi/ wp-content/uploads/Tietosuojaseloste-Ansaintarekisteri-1.pdf. Accessed September $28,2018$.

16. Statistics Finland. Official Statistics of Finland (OSF): causes of death [e-publication]. Helsinki: Statistics Finland. Available at: stat.fi/til/ksyyt/index_en.html. Accessed November 20, 2017.

17. R Core Team. R: A Language and Environment for Statistical Computing. Vienna: R Foundation for Statistical Computing; 2014. Available at: R-project.org/. Accessed November 3, 2017.

18. Harrell FE. Regression Modeling Strategies: With Applications to Linear Models, Logistic Regression, and Survival Analysis. New York: Springer; 2001.

19. Hilbe J. Logistic Regression Models. Boca Raton, FL: Chapman \& Hall/CRC, Taylor \& Francis; 2009.

20. Hosmer D, Lemeshow S. Applied Logistic Regression, 2nd ed. New York: Wiley; 2000.

21. Swihart BJ, Caffo B, James BD, Strand M, Schwartz BS, Punjabi NM. Lasagna plots: a saucy alternative to spaghetti plots. Epidemiology 2010;21:621-625.

22. Tanaka H, Toyonaga T, Hashimoto H. Functional and occupational characteristics predictive of a return to work within 18 months after stroke in Japan: implications for rehabilitation. Int Arch Occup Environ Health 2014;87:445-453.

23. McAllister S, Derrett S, Audas R, Herbison P, Paul C. Do different types of financial support after illness or injury affect socio-economic outcomes? A natural experiment in New Zealand. Soc Sci Med 2013;85:93-102.

24. Saeki S, Toyonaga T. Determinants of early return to work after first stroke in Japan. J Rehabil Med 2010;42:254-258.

25. Lindstrom B, Roding J, Sundelin G. Positive attitudes and preserved high level of motor performance are important factors for return to work in younger persons after stroke: a national survey. J Rehabil Med 2009;41:714-718.

26. Saeki S, Hachisuka K. The association between stroke location and return to work after first stroke. J Stroke Cerebrovasc Dis 2004;13:160-163.

27. Kela. Kela benefits [online]. Available at: kela.fi/web/en/operations-kela-benefits. Accessed July 9, 2018. 


\section{Neurology}

Return to work after ischemic stroke in young adults: A registry-based follow-up study

Karoliina Aarnio, Jorge Rodríguez-Pardo, Bob Siegerink, et al.

Neurology 2018;91;e1909-e1917 Published Online before print October 12, 2018

DOI 10.1212/WNL.0000000000006510

This information is current as of October 12, 2018

\section{Updated Information \& Services \\ Supplementary Material \\ References \\ Citations \\ Subspecialty Collections}

Permissions \& Licensing

Reprints including high resolution figures, can be found at: http://n.neurology.org/content/91/20/e1909.full

Supplementary material can be found at: http://n.neurology.org/content/suppl/2020/03/04/WNL.0000000000006 510.DC1

This article cites 19 articles, 8 of which you can access for free at: http://n.neurology.org/content/91/20/e1909.full\#ref-list-1

This article has been cited by 2 HighWire-hosted articles: http://n.neurology.org/content/91/20/e1909.full\#\#otherarticles

This article, along with others on similar topics, appears in the following collection(s):

Infarction

http://n.neurology.org/cgi/collection/infarction

Outcome research

http://n.neurology.org/cgi/collection/outcome_research

Stroke in young adults

http://n.neurology.org/cgi/collection/stroke_in_young_adults

Information about reproducing this article in parts (figures,tables) or in its entirety can be found online at:

http://www.neurology.org/about/about_the_journal\#permissions

Information about ordering reprints can be found online:

http://n.neurology.org/subscribers/advertise

Neurology ${ }^{\circledR}$ is the official journal of the American Academy of Neurology. Published continuously since 1951, it is now a weekly with 48 issues per year. Copyright Copyright ( 2018 The Author(s). Published by Wolters Kluwer Health, Inc. on behalf of the American Academy of Neurology.. All rights reserved. Print ISSN: 0028-3878. Online ISSN: 1526-632X.

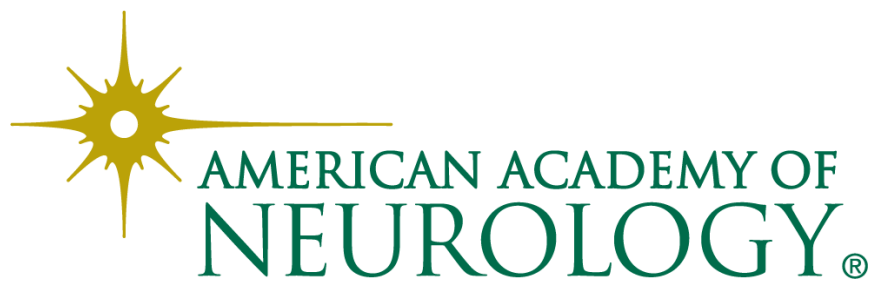

